EXTENDED REPORT

\title{
Relative risk of knee chondrocalcinosis in siblings of index cases with pyrophosphate arthropathy
}

\author{
W Zhang, R Neame, S Doherty, M Doherty
}

Ann Rheum Dis 2004;63:969-973. doi: 10.1136/ard.2003.015206

See end of article for authors' affiliations

Correspondence to

Dr W Zhang, Academic

Rheumatology, Clinical

Sciences Building, City

Hospital, Nottingham NG5

1PB, UK; Weiya.Zhang@

nottingham.ac.uk

Accepted

19 November 2003

\begin{abstract}
Objectives: To examine the genetic contribution to common, apparently sporadic, radiographic knee chondrocalcinosis (CC) and pyrophosphate arthropathy (PA).

Method: (1) Design: radiographic sibling study. Comparison of the prevalences of knee CC and PA in siblings of index cases with PA with those in the community. (2) Subjects: 80 index cases with PA listed for total knee replacement; 122 of their siblings aged $\geqslant 40$ years; and 1729 participants from community knee pain surveys who had undergone knee radiographs. (3) Main outcome measure: odds ratios of knee $\mathrm{CC}$ and PA in siblings versus community participants.

Results: The prevalence of knee CC was 13\% (15/116) in the siblings and $6.9 \%(119 / 1727)$ in the community participants. The adjusted odds ratio (aOR) was $1.2,95 \%$ confidence interval (CI) 0.6 to 2.3 . The main risk factors for knee CC were age, knee pain, and knee OA. The prevalence of knee PA was $7 \%$ $(9 / 122)$ in the siblings and 3.4\% (59/1729) among the community participants (aOR $=1.1,95 \% \mathrm{Cl} 0.4$ to 2.7). The main risk factors for PA were age and knee pain. The age, sex, and knee pain standardised prevalence of PA in the Nottingham community aged $\geqslant 40$ was $2.40 \%$.

Conclusion: The risk of knee CC and PA in siblings of index cases with PA is no higher than that in the general population. Although rare familial CC is recognised, this study suggests that no major genetic predisposition to $\mathrm{CC}$ occurs in common symptomatic knee $\mathrm{OA}$.
\end{abstract}

C hondrocalcinosis (CC), refers to calcification within cartilage, and is usually due to deposition of calcium pyrophosphate dihydrate (CPPD) crystals. The sites most commonly affected are the knee, wrist, and symphysis pubis. CC is readily visualised on plain radiographs. ${ }^{1}$ It may be asymptomatic or associated with acute and chronic pain syndromes and structural changes of osteoarthritis (OA)..$^{2-4}$ In Europe the term "pyrophosphate arthropathy" (PA) is often used for the combination of CC and structural OA. ${ }^{2-4}$ We recently reported a standardised prevalence of radiographic CC of $4.5 \%$ in Nottingham, UK, in those aged 40-79 years, rising from $4 \%$ in those aged $55-59$ to $18 \%$ in those aged $80-84 .^{5}$ Similar prevalence estimates for CC have been obtained in the US Framingham cohort. ${ }^{6}$ However, the community prevalence of PA has not been reported.

A number of risk factors for $\mathrm{CC}$ are recognised. Aging is a major risk factor in all studies. Joint damage and OA are also considered common predisposing factors, ${ }^{247}$ though the association with OA may largely reflect a more direct association with osteophytes. ${ }^{5}$ Risk factors that are considered less common or rare are familial predisposition ${ }^{8}$ and metabolic diseases that affect inorganic pyrophosphate metabolism. ${ }^{9}$ Most reports of familial CC are of monogenic disorders with phenotypes ranging from isolated CC to mild or severe PA, often with florid early onset polyarticular CC. ${ }^{4}$ However, less florid familial forms with later onset oligoarticular CC or PA are also reported. ${ }^{4} 1011$

The role of genetic factors in predisposition to common, apparently sporadic CC and PA remains unknown. Although McCarty et al initially found a $25 \%$ prevalence of familial CC in their case series, ${ }^{12}$ there have been just three systematic studies, all undertaken in Spain, to determine the prevalence of CC in first degree relatives of patients with apparently sporadic CC or PA. All concur in reporting high prevalence rates of $11 \%,{ }^{13} 26 \%,{ }^{14}$ and $28 \% .{ }^{15}$ However, caveats to these studies include focused selection of index cases from rheumatology units; small numbers of index cases; high non-participation rates in index cases and relatives; and, importantly, absence of a community control population. We therefore undertook the present controlled study to determine the relative risk of CC and PA in siblings of index cases with PA awaiting knee surgery. The Nottingham Total Joint Replacement Register provides a convenient cohort of index cases with clinically significant PA referred from the whole county of Nottinghamshire. We compared the prevalence of knee CC and PA in siblings of these index cases with the prevalence in a large sample of the Nottingham community, adjusting for the potential risk factors age, sex, body mass index (BMI), and presence of knee pain. A secondary objective was to determine the first ever standardised community prevalence estimate of PA.

\section{METHODS}

Approval for this study was obtained from the local research ethics committee.

\section{Participants}

Three stages were followed to identify participants: (a) identification of index cases aged $\geqslant 40$ years awaiting total knee replacement, with both radiographic OA and CC (that is, PA); (b) prospective recruitment of siblings of the index cases with $\mathrm{PA}$ aged $\geqslant 40$ years, irrespective of whether or not they had knee symptoms or known OA or CC; and (c) control participants in the existing databases derived from two Nottingham community knee pain studies. ${ }^{16} 17$

Abbreviations: aOR, adjusted odds ratio; $\mathrm{BMI}$, body mass index; $\mathrm{CC}$, chondrocalcinosis; $\mathrm{Cl}$, confidence interval; $\mathrm{CPPD}$, calcium pyrophosphate dihydrate; OA, osteoarthritis; PA, pyrophosphate arthropathy; PFJ, patellofemoral joint; TFJ, tibiofemoral joint 


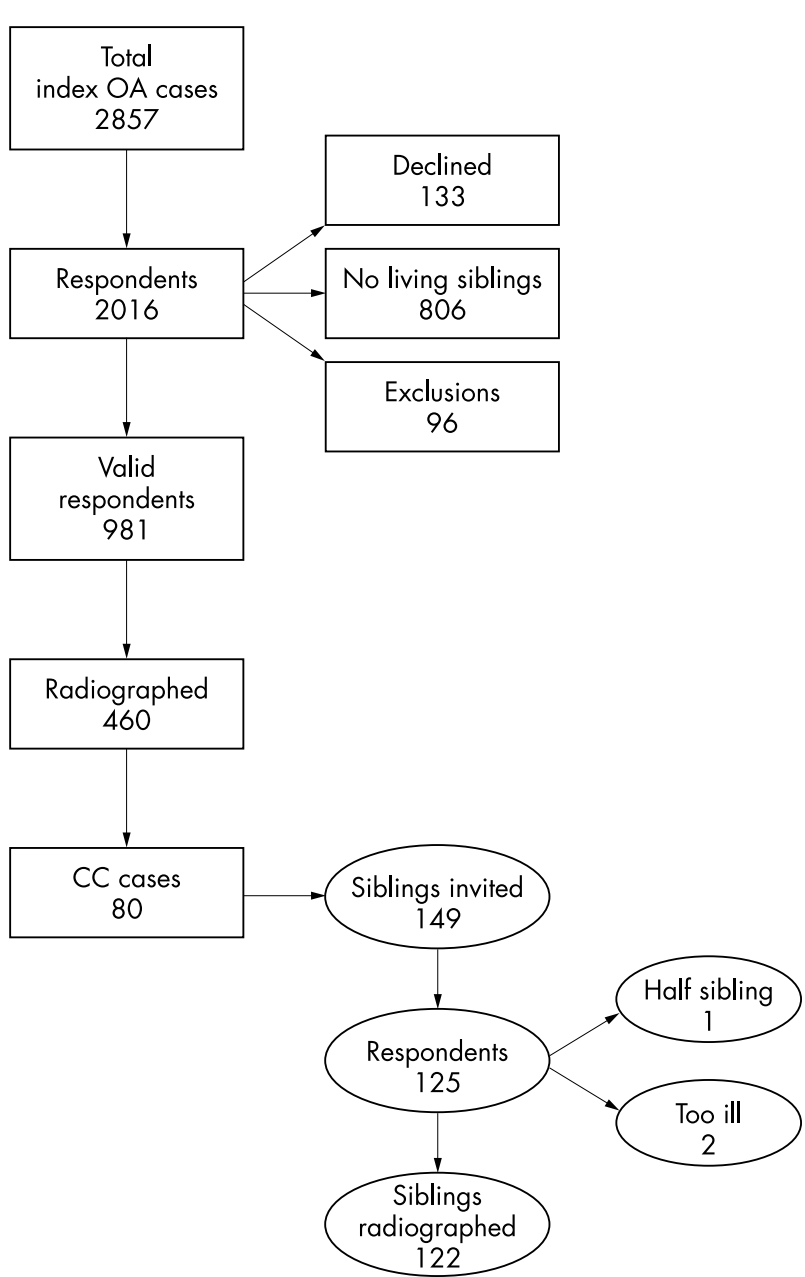

Figure 1 Recruitment of index cases and siblings.

\section{Case ascertainment \\ Index cases}

Index cases with PA were identified from consecutive patients aged $\geqslant 40$ years with knee OA who were awaiting total knee replacement at any of the three principal Nottinghamshire orthopaedic centres between 1997 and 2000. Preoperative knee radiographs were reviewed. Subjects with CC in any knee compartment were included. Index cases were sent a questionnaire asking for the contact details of all of their siblings, irrespective of whether they were thought to have arthritis. Non-responders were mailed again once after 4 weeks.

\section{Siblings of index cases with PA}

Siblings were identified from the questionnaire responses of index cases. Siblings aged $<40$ and half-siblings were excluded. Siblings were sent a postal questionnaire and were invited to undergo knee radiographs and metrologist examination, irrespective of whether or not they had knee symptoms or were thought to have arthritis. Those who did not reply were mailed again once after 4 weeks.

\section{Community sample}

Data and radiographs from two Nottingham community knee pain studies performed at our centre between 1995 and 1999 were used. In these studies ${ }^{16}{ }^{17}$ random samples of people aged $\geqslant 40$ years registered at general practices in Nottingham had been mailed questionnaires about knee pain, and a selection of respondents were invited to undergo knee

\begin{tabular}{|c|c|c|c|}
\hline Characteristics & Siblings & Community & p Value \\
\hline Number & 122 & 1729 & \\
\hline Age, mean (SD) & $70.3(8.3)$ & $63.7(9.4)$ & 0.00 \\
\hline \multicolumn{4}{|l|}{ Sex, No (\%) } \\
\hline Male & $48(39)$ & $644(37.2)$ & 0.70 \\
\hline Female & $74(61)$ & $1085(62.8)$ & \\
\hline BMl, mean (SD) & $26.6(4.9)$ & $26.8(4.3)$ & 0.52 \\
\hline Knee pain, No (\%) & $57 / 97(59)$ & $1000 / 1729(57.8)$ & 0.92 \\
\hline
\end{tabular}

radiographs and metrologist examination. Exclusion criteria included total knee replacement, terminal illness, and incapacity to give informed consent. ${ }^{5} 1617$

\section{Data collection}

Data collected from all postal questionnaires included age, sex, and presence or absence of knee pain (defined as ever having knee pain on most days for at least a month, and having pain within the past year). Metrologists measured the BMI in $\mathrm{kg} / \mathrm{m}^{2}$ in those who underwent radiographic examination.

\section{Radiographic assessment}

All radiographs were taken under the same standardised conditions, and were weightbearing, fully extended, anteroposterior views $(55 \mathrm{kV}, 8 \mathrm{~mA} / \mathrm{s}$, full scale deflection $100 \mathrm{~cm})$, and skyline $30^{\circ}$ flexion views $(60 \mathrm{kV}, 10 \mathrm{~mA} / \mathrm{s}$, full scale deflection $100 \mathrm{~cm}$ ) using standard Fuji film.

A single observer (RN) read all radiographs. Sibling and community radiographs were mixed and read blind. Films were read first for OA and then for CC. An independent researcher selected 40 sets of films, representing a wide range of radiographic changes, which were re-read by the study observer to test reproducibility.

Tibiofemoral joint (TFJ) views were assigned a global Kellgren and Lawrence grade for OA. ${ }^{18}$ An adaptation of a previously validated line drawing atlas was used to score osteophyte (0-5) at eight sites (medial and lateral femur, medial and lateral tibia, medial and lateral patella, and medial and lateral femoral trochlea). ${ }^{19}$ Joint space narrowing was assessed for each compartment (medial TFJ, lateral TFJ, medial patellofemoral (PFJ) and lateral PFJ).

OA was defined as a Kellgren and Lawrence grade $\geqslant 2$ at the TFJ, or definite joint space narrowing and definite osteophyte at the PFJ. CC was recorded as present or absent, and the site of CC (TFJ or PFJ, medial or lateral, hyaline or fibrocartilage or capsular) was recorded.

\section{Statistical analysis}

For both groups the prevalence of each of the following conditions was estimated:

- All CC (CC whether or not OA was present)

- Isolated CC (CC in the absence of OA)

- All OA (OA whether or not CC was present)

- Isolated OA (OA in the absence of CC)

- PA (CC with OA).

As the number of siblings contributed from each family was different, the risk might vary from family to family if it was not independent and hence influence the overall risk estimation for the sibling group. We therefore undertook a correlation analysis using Pearson's $\chi^{2}$ test to examine whether the number of siblings contributed would influence the risk for the above conditions. 
Table 2 Prevalence and odds ratios of knee chondrocalcinosis, osteoarthritis, and pyrophosphate arthropathy

\begin{tabular}{|c|c|c|c|c|}
\hline & \multicolumn{2}{|c|}{ Prevalence (\%) } & \multirow[b]{2}{*}{ OR $(95 \% \mathrm{CI})$} & \multirow[b]{2}{*}{ aOR $(95 \% \mathrm{Cl})$} \\
\hline & Siblings & Community & & \\
\hline $\begin{array}{l}\text { All CC } \\
\text { Isolated CC } \\
\text { All OA } \\
\text { Isolated OA } \\
\text { PA (CC+OA) }\end{array}$ & $\begin{array}{l}15 / 116(13) \\
6 / 122(5) \\
62 / 120(52) \\
48 / 122(39) \\
9 / 122(7)\end{array}$ & $\begin{array}{c}119 / 1727(6.9) \\
60 / 1729(3.5) \\
466 / 1725(27.0) \\
405 / 1729(23.4) \\
59 / 1729(3.4)\end{array}$ & $\begin{array}{l}2.01(1.13 \text { to } 3.56)^{*} \\
1.44(0.61 \text { to } 3.40) \\
2.89(1.99 \text { to } 4.20)^{* *} \\
2.12(1.45 \text { to } 3.10)^{* *} \\
2.25(1.09 \text { to } 4.66)^{*}\end{array}$ & $\begin{array}{l}1.16(0.58 \text { to } 2.29) \\
1.07(0.41 \text { to } 2.78) \\
2.17(1.35 \text { to } 3.48)^{* *} \\
1.74(1.10 \text { to } 2.76)^{*} \\
1.09(0.44 \text { to } 2.68)\end{array}$ \\
\hline \multicolumn{5}{|c|}{$\begin{array}{l}\mathrm{CC} \text {, chondrocalcinosis; } \mathrm{OA} \text {, osteoarthritis; } \mathrm{PA} \text {, pyrophosphate arthropathy; } \mathrm{OR} \text {, odds ratio; } \mathrm{Cl} \text {, confidence } \\
\text { interval; aOR, adjusted } \mathrm{OA} \text { by age, sex, BMI, knee pain, } \mathrm{CC} \text { (for all } \mathrm{OA} \text { only) and } \mathrm{OA} \text { (for all } \mathrm{CC} \text { only). } \\
{ }^{*} \mathrm{p} \leqslant 0.05 ;{ }^{* *} \mathrm{p} \leqslant 0.01 \text {. }\end{array}$} \\
\hline
\end{tabular}

Crude odds ratios of each condition in siblings versus community participants were calculated and adjustment made for age, sex, BMI, and knee pain using logistic regression. All analyses were undertaken using SPSS, version 11.

The age, sex, and knee pain adjusted estimate for the prevalence of PA was calculated by standardisation using data from the 1991 census $^{20}$ and the knee pain survey data. ${ }^{21}$

\section{RESULTS}

\section{Response rate: index cases}

Questionnaires were mailed to 2857 index cases. After the second mailing 2016 replies were received, a response rate of $70.6 \%$ (fig 1). From these, the following were excluded: 133 who did not want to participate, 806 with no living siblings, 32 who did not supply siblings' contact details, 7 with halfsiblings, 30 who had died, and 27 with diagnoses other than OA. Of the remaining 981 index cases, 460 underwent knee radiographs and 80 of these had both radiographic OA and CC.

\section{Response rate: siblings}

Invitations were mailed to 149 siblings of the 80 index cases, including 15 who were not local; 125 replies were received, giving a response rate of $83.9 \%$ (fig 1). From these, one halfsibling and two siblings who subsequently were too ill to come for $x$ ray examination were excluded.

\section{Response rate: community sample}

The overall response rate to the two community postal questionnaires was $70.1 \%$ after the second mailing; 1729 participants with radiographs were available for the analysis. Further details of this sample have been reported previously. ${ }^{5}$

\section{Participant characteristics}

Siblings were older than community participants, but the two groups did not differ for sex distribution, BMI, or prevalence of knee pain (table 1).

\section{Reproducibility}

Intraobserver reproducibility for Kellgren and Lawrence grade was good $(\kappa=0.74$ for the right knee, 0.84 for the left knee). Good agreement was also seen using the line atlas. The value of $\kappa$ for joint space narrowing scores ranged from 0.69 (left medial PFJ) to 0.85 (left medial TFJ). The $\kappa$ value for osteophyte scores ranged from 0.70 (right lateral femur) to 0.90 (left medial trochlea). Reproducibility for the presence of CC was very good $(\kappa=0.9)$.

\section{Prevalence of $\mathrm{CC}, \mathrm{OA}$, and $\mathrm{PA}$}

The crude prevalence of all CC or PA was higher among the siblings than among the community controls, but there was no difference in the prevalence of isolated CC once OA cases were excluded (table 2). By contrast, the prevalence of OA in siblings was significantly higher than in the community controls, irrespective of the presence of CC.

\section{Adjusted odds ratios of $\mathrm{CC}, \mathrm{OA}$, and PA}

Although the crude odds ratios (ORs) showed that the risk of all CC was higher in the siblings than in the community ( $\mathrm{OR}=2.01,95 \%$ confidence interval (CI) 1.13 to 3.56 ), after adjusting for age, sex, BMI, knee pain, and knee OA the difference was not statistically significant $(\mathrm{aOR}=1.16,95 \%$ CI 0.58 to 2.29; table 2). The risk factors for all CC were age, knee pain, and knee OA (table 3). Siblings were not at increased risk. Isolated CC was associated with age only. By contrast, the risk of OA was higher in siblings. OA was also associated with age, BMI, and knee pain. However, the risk of PA was not higher in siblings after adjusting for age, sex, BMI, and knee pain. The risk factors for PA were age and knee pain only (table 3 ).

To examine whether the risk in the sibling group increased with the number of siblings contributed from different families, a correlation analysis was undertaken. The results showed that the risk did not increase with the number of

Table 3 Risk factors and adjusted odds ratios for knee chondrocalcinosis, osteoarthritis, and pyrophosphate arthropathy

\begin{tabular}{|c|c|c|c|c|c|c|c|}
\hline & $\begin{array}{l}\text { Sibling of PA } \\
\text { (present/absent) }\end{array}$ & $\begin{array}{l}\text { Age } \\
\text { (per } 10 \text { year } \\
\text { increase) }\end{array}$ & $\begin{array}{l}\text { Sex } \\
\text { (Female/male) }\end{array}$ & $\begin{array}{l}\text { BMI }\left(\mathrm{kg} / \mathrm{m}^{2}\right) \\
\text { (WHO criteriont) }\end{array}$ & $\begin{array}{l}\text { Knee pain } \\
\text { (present/absent) }\end{array}$ & $\begin{array}{l}\mathrm{CC} \\
\text { (present/absent) }\end{array}$ & $\begin{array}{l}\text { OA } \\
\text { (present/absent) }\end{array}$ \\
\hline All CC & $\begin{array}{l}1.16 \\
(0.58 \text { to } 2.29)\end{array}$ & $\begin{array}{l}2.25 \\
(1.79 \text { to } 2.82)^{* *}\end{array}$ & $\begin{array}{l}0.76 \\
(0.52 \text { to } 1.10)\end{array}$ & $\begin{array}{l}0.90 \\
(0.70 \text { to } 1.14)\end{array}$ & $\begin{array}{l}1.76 \\
(1.15 \text { to } 2.69)^{* *}\end{array}$ & N/A & $\begin{array}{l}1.71 \\
(1.15 \text { to } 2.55)^{* *}\end{array}$ \\
\hline Isolated CC & $\begin{array}{l}1.07 \\
(0.41 \text { to } 2.78)\end{array}$ & $\begin{array}{l}1.87 \\
(1.41 \text { to } 2.48)^{\star *}\end{array}$ & $\begin{array}{l}0.92 \\
(0.55 \text { to } 1.52)\end{array}$ & $\begin{array}{l}0.87 \\
(0.63 \text { to } 1.20)\end{array}$ & $\begin{array}{l}1.35 \\
(0.80 \text { to } 2.30)\end{array}$ & N/A & N/A \\
\hline All OA & $\begin{array}{l}2.17 \\
(1.35 \text { to } 3.48)^{* *}\end{array}$ & $\begin{array}{l}2.15 \\
(1.83 \text { to } 2.45)^{* *}\end{array}$ & $\begin{array}{l}0.96 \\
(0.76 \text { to } 1.21)\end{array}$ & $\begin{array}{l}1.48 \\
(1.27 \text { to } 1.71)^{* *}\end{array}$ & $\begin{array}{l}3.74 \\
(2.89 \text { to } 4.83)^{\star *}\end{array}$ & $\begin{array}{l}1.70 \\
(1.14 \text { to } 2.53)^{* *}\end{array}$ & N/A \\
\hline Isolated OA & $\begin{array}{l}1.74 \\
(1.10 \text { to } 2.76)^{*}\end{array}$ & $\begin{array}{l}1.85 \\
(1.63 \text { to } 2.10)^{* *}\end{array}$ & $\begin{array}{l}1.02 \\
(0.81 \text { to } 1.29)\end{array}$ & $\begin{array}{l}1.48 \\
(1.28 \text { to } 1.72)^{* *}\end{array}$ & $\begin{array}{l}3.27 \\
(2.52 \text { to } 4.24)^{\star *}\end{array}$ & N/A & N/A \\
\hline PA & $\begin{array}{l}1.09 \\
(0.44 \text { to } 2.68)\end{array}$ & $\begin{array}{l}2.88 \\
(2.10 \text { to } 3.93)^{\star *}\end{array}$ & $\begin{array}{l}0.64 \\
(0.38 \text { to } 1.06)\end{array}$ & $\begin{array}{l}1.01 \\
(0.72 \text { to } 1.41)\end{array}$ & $\begin{array}{l}2.97 \\
(1.68 \text { to } 5.43)\end{array}$ & N/A & N/A \\
\hline
\end{tabular}

$\mathrm{CC}$, chondrocalcinosis; $\mathrm{OA}$, osteoarthritis; $\mathrm{PA}$, pyrophosphate arthropathy; N/A, not appropriate. ${ }^{*} p \leqslant 0.05 ;{ }^{* *} p \leqslant 0.01$.

TWHO criteria for BMl: normal $\left(<25 \mathrm{~kg} / \mathrm{m}^{2}\right)$, overweight $\left(25-29.99 \mathrm{~kg} / \mathrm{m}^{2}\right)$, and obese $\left(\geqslant 30 \mathrm{~kg} / \mathrm{m}^{2}\right)$. 


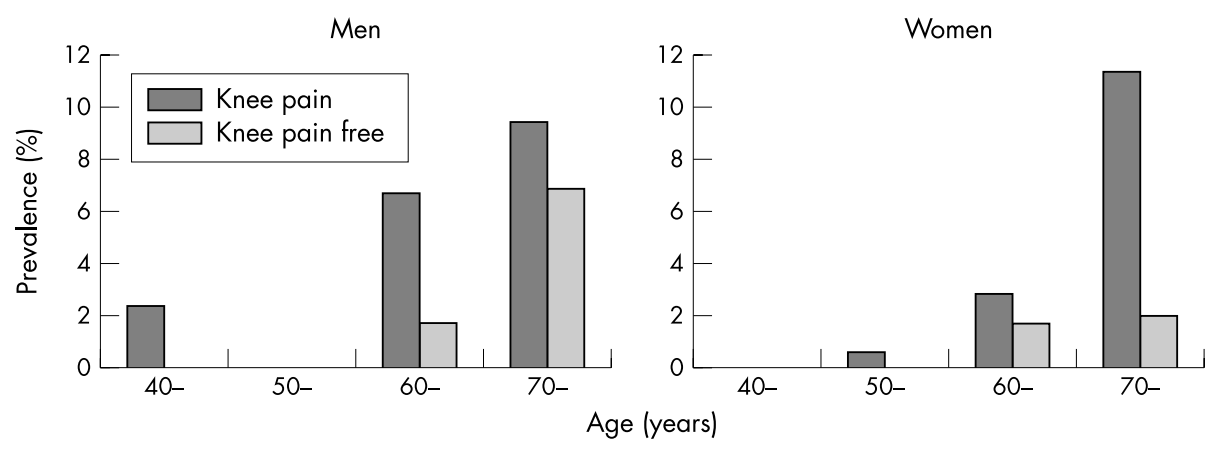

Figure 2 Prevalence of pyrophosphate arthropathy in the Nottingham community.

siblings contributed $(\mathrm{p}=0.41,0.37,0.36,0.14$, and 0.66 for all CC, isolated CC, all OA, isolated OA, and PA, respectively).

\section{Standardised prevalence of PA}

Figure 2 shows the rising prevalence of PA in both men and women with age. Adjustment for age, sex, and presence of knee pain gave a standardised prevalence of $2.40 \%$ for PA in adults aged $>40$ in Nottingham.

\section{DISCUSSION}

This study did not show evidence of genetic predisposition to CC or PA in siblings of index subjects with symptomatic PA sufficient to warrant joint replacement. The crude prevalence of CC that we found in siblings (13\%) was within the range that has been reported previously $(11-28 \%)$, and is very similar to the $11 \%$ prevalence in the study by RodriguezValverde et al. ${ }^{13}$ Several factors may have led to the prevalence in our study being at the lower end of the estimates that have been reported. Firstly, we restricted the study to siblings rather than to all available relatives. ${ }^{13-15}$ Secondly, we undertook radiographic screening of knees only, rather than knees, pelvis, and hands. ${ }^{13-15}$ Thirdly, we selected consecutive index cases from a surgical register rather than patients from rheumatology clinics. Another factor is that we had a higher participation rate than in the other three studies and therefore possibly less selection bias towards relatives with symptomatic disease.

Importantly, our study is the only one that includes comparison of the prevalence of CC in first degree relatives with that observed in community subjects after adjustment for potential risk factors such as age and sex. Our standardised community prevalence of $\mathrm{CC}^{5}$ is very similar to that reported in the Framingham population. ${ }^{6}$ Direct age-sex standardisation applying our estimates to the Framingham population sample gives an expected prevalence of $10.4 \%$, and the prevalence observed in that population was $8.1 \%{ }^{6}$ It therefore seems unlikely that either a significant underestimation of sibling prevalence or an overestimation of community prevalence of CC explains the lack of genetic risk that we found.

We investigated risk factors for five possible situations: all CC (CC whether or not OA was present), isolated CC (CC in the absence of OA), all OA (OA whether or not CC was present), isolated OA (OA in the absence of CC), and PA (CC with $\mathrm{OA}$ ). The risk factors examined were family aggregation, age, sex, BMI, and knee pain. Although the crude prevalence of all CC in siblings was higher than in the community $(\mathrm{OR}=2.01,95 \% \mathrm{CI} 1.13$ to 3.56$)$, after adjusting for OA the risk of all CC in siblings did not differ significantly from that in the community. In addition to OA, risk factors for all CC were age and knee pain. However, isolated CC was associated only with advancing age. This suggests that sporadic isolated CC is predominantly an age related condition. Investigation of the association of CC with knee pain was limited by our definition of knee pain, which predominantly relates to chronic pain. Short, self limiting episodes of pseudogout therefore might have been missed. However, the observation that knee pain was associated with each scenario except for isolated CC, suggests that it is structural change rather than CC itself that is associated with chronic pain. Unlike hospital studies, where female predominance is almost universally reported, ${ }^{2}{ }^{13-15} 22$ there was no association of CC or PA with sex. This concurs with the findings for CC among the community participants. ${ }^{5}$ We found no association of CC with BMI. This has been examined only infrequently, the theoretical basis for such an association being that excessive mechanical loading of joints can stimulate chondrocytes to release more ATP, a potent source of extracellular pyrophosphate. ${ }^{23}$

None of the three scenarios of CC demonstrated statistically significant sibling aggregation. As expected, and in contrast, there was a strong genetic contribution to OA. It is noteworthy that although both familial aggregation and obesity were associated both with all OA and isolated OA, these associations were lost when OA was examined in association with PA. This might suggest that the structural changes of PA represent a distinct entity separate from OA. Previous reports have highlighted features that may distinguish PA from OA, such as marked cyst formation, a "hypertrophic" bone response with florid osteophyte formation, and an atypical distribution within and between joints. ${ }^{44}$ The differences in risk factors seen in our study lend epidemiological support to the concept that PA is a discrete subset within the broad spectrum of "OA".

Absence of familial predisposition to $\mathrm{CC}$ and PA is consistent with recent studies of the genetics of familial CC. Mutations of the ANKH gene on chromosome $5 \mathrm{p}$ have been identified as the cause of familial CC in separate kindreds from the UK, France, and the USA. ${ }^{25-27}$ The ANKH gene encodes the ank protein that functions as an ion channel for transport of pyrophosphate across the cell membrane to the extracellular space. ${ }^{25} 28$ A search for ANKH mutations in 95 consecutive patients referred to hospital with CC in Nottingham found a prevalence of $<1 \%$, suggesting that this major cause of reported familial CC is a rare cause in community subjects with apparently sporadic CC.

There are a number of caveats to this study. Firstly, the index cases all had symptomatic PA and different results might have been obtained if index cases with asymptomatic PA or isolated CC had been included. Secondly, although the largest study of its kind, the size of the index and sibling groups remains small. Therefore, possibly, there were insufficient numbers to demonstrate a more modest genetic influence. Thirdly, the radiograph is relatively insensitive for detection of crystals, and although CPPD is the commonest 
cause of radiographic CC, specific crystal identification was not attempted. Studies based on synovial fluid analysis might be more sensitive and specific for crystal detection, but such an approach is impractical for investigation of community controls. Another caveat is that we did not exclude underlying metabolic disease in participants. This is unlikely to have influenced our findings, however, because other studies that have undertaken systematic screening of family members have identified no cases of metabolic predisposition. ${ }^{13}{ }^{15}$

This is the first study to report the community prevalence of PA $(2.40 \%)$ in community subjects aged $>40$, standardised for age, sex, and presence of knee pain. As with $\mathrm{CC}^{5}$ there was no difference in the prevalence of PA between women and men. This is contrary to the often marked female preponderance reported in hospital series and presumably reflects the marked confounding by age and the higher proportion of women in the older population. From these data it appears that just over half of all cases of CC in the community (standardised prevalence $4.5 \%$ ) are associated with structural changes of PA.

\section{ACKNOWLEDGEMENTS}

We are indebted to all participants in these studies; the Arthritis Research Campaign, UK, for funding of an ARC non-clinical senior lectureship (WZ; ARC grant DO565) and infrastructure support (ARC ICAC grant DO593); and GlaxoSmithKline, USA, for financial support (RN).

\section{Authors' affiliations}

W Zhang, R Neame, S Doherty, M Doherty, Academic Rheumatology, University of Nottingham, Nottingham, UK

\section{REFERENCES}

1 Genant HK. Roentgenographic aspects of calcium pyrophosphate dihydrate crystal deposition disease (pseudogout). Arthritis Rheum 1976;19:307-28.

2 Dieppe PA, Alexander GM, Jones H, Doherty M, Scott DG, Manhire A, et al. Pyrophosphate arthropathy: a clinical and radiological study of 106 cases. Ann Rheum Dis 1982;41:371-6.

3 Silman AJ, Hochberg MC. Epidemiology of the rheumatic diseases. Oxford: Oxford Medical Publications, 1993.

4 Doherty M. Calcium pyrophosphate dihydrate. In: Hochberg MC, Silman AJ, Smolen JS, Weinblatt ME, Weisman MH, eds. Rheumatology. 3rd ed. St Louis: Mosby, 2003:1937-50.

5 Neame RL, Carr A, Muir K, Doherty M. UK community prevalence of knee chondrocalcinosis: evidence that correlation with osteoarthritis is through a shared association with osteophyte. Ann Rheum Dis 2003;62:513-18.

6 Felson DT, Anderson JJ, Naimark A, Kannel W, Meenan RF. The prevalence of chondrocalcinosis in the elderly and its association with knee osteoarthritis: the Framingham study. J Rheumatol 1989;16:1241-5.
7 Doherty M, Watt I, Dieppe PA. Localised chondrocalcinosis in postmeniscectomy knees. Lancet 1982;2:1207-10.

8 Zitnan D, Sitaj S. Chondrocalcinosis articularis. Ann Rheum Dis 1963:22:142-68.

9 Jones AC, Chuck AJ, Arie EA, Green DJ, Doherty M. Diseases associated with calcium pyrophosphate deposition disease. Semin Arthritis Rheum 1992;22:188-202.

10 Riestra JL, Sanchez A, Rodriguez-Valverde V, Alonson JL. Radiographic features of hereditary articular chondrocalacinosis. A comparative study with the sporadic type. Clin Exp Rheumatol 1988;6:369-72.

11 Doherty M, Hamilton E, Henderson J, Misra H, Dixey J. Familial chondrocalcinosis due to calcium pyrophosphate dihydrate crystal deposition in English families. Br J Rheumatol 1991;30:10-15.

12 McCarty DJ, Kohn NN, Faires JS. The significance of calcium phosphate crystals in the synovial fluid of arthritic patients: the pseudogout syndrome. I. Clinical aspects. Ann Intern Med 1962;5:711-36.

13 Rodriguez-Valverde V, Tinture T, Zuniga M, Pena J, Gonzalez A. Familial chondrocalcinosis. Prevalence in northern Spain and clinical features in five pedigrees. Arthritis Rheum 1980;23:471-8.

14 Balsa A, Martin-Mola E, Gonzalez T, Cruz A, Ojeda S, Gijon-Banos J. Familial articular chondrocalcinosis in Spain. Ann Rheum Dis 1990;49:531-5.

15 Dapica MPF, Gomez-Reino JJ. Familial chondrocalcinosis in the Spanish population. J Rheumatol 1986;13:631-3.

16 O'Reilly SC, Muir KR, Doherty M. Knee pain and disability in the Nottingham community: association with poor health status and psychological distress. $\mathrm{Br} J$ Rheumatol 1998;37:870-3.

17 Thomas KS, Muir KR, Doherty M, Jones AC, O'Reilly SC, Bassey EJ. Home based exercise programme for knee pain and knee osteoarthritis: randomised controlled trial. BMJ 2002;325:752-6.

18 Kellgren JK, Lawrence JS. The epidemiology of chronic rheumatism. Vol II. Atlas of Standard Radiographs of Arthritis. Oxford: Blackwell Scientific Publications, 1963.

19 Nagaosa Y, Mateus M, Hassan B, Lanyon P, Doherty M. Development of a logically derived line drawing atlas for grading of knee osteoarthritis. Ann Rheum Dis 2000;9:587-95.

20 Census. County report: Nottingham (Part 1). London: HMSO, 1992.

21 O'Reilly SC, Muir K, Doherty M. Screening for knee pain in osteoarthritis: which question? Ann Rheum Dis 1996;55:931-3.

22 Bergstrom G, Bjelle A, Sorensen LB, Sundh V, Svanborg A. Prevalence of rheumatoid arthritis, osteoarthritis, chondrocalcinosis and gouty arthritis at age 79. J Rheumatol 1986;13:527-34.

23 Graff RD, Lazarowski ER, Banes AJ, Lee GM. ATP release by mechanically loaded porcine chondrons in pellet culture. Arthritis Rheum 2000;43:1571-9.

24 Resnick D, Niwayama G, Goergen TG, Utsinger PD, Shapiro RF,

Haselwood DH, et al. Clinical, radiographic and pathologic abnormalities in calcium pyrophosphate deposition disease (CPPD): pseudogout. Radiology 1977;122:1-15.

25 Pendleton A, Johnson MD, Hughes A, Gurley KA, Ho AM, Doherty M, et al. Mutations in ANKH cause chondrocalcinosis. Am J Hum Genet 2002:71:933-40.

26 Williams CJ, Zhang Y, Timms A, Bonavita G, Caeiro F, Broxholme J, et al. Autosomal dominant familial calcium pyrophosphate dihydrate deposition disease is caused by mutation in the transmembrane protein ANKH. Am J Hum Genet 2002;71:985-91.

27 Williams CJ, Pendleton A, Bonavita G, Reginato AJ, Hughes AE, Peariso S, et al. Mutations in the amino terminus of ANKH in 2 US families with calcium pyrophosphate dihydrate deposition disease. Arthritis Rheum, 2003;48:2627-31

28 Ho A, Johnson M, Kingsley D. Role of the mouse ank gene in control of tissue calcification and arthritis. Science 2000;289:265-70. 